\title{
Miradas al pasado con repercusiones para el presente
}

\author{
Alma Dorantes González
}

María Teresa Fernández ACEVES, CARMEN RAmos

ESCANDON Y SUSIE PORTER (coords.), 2006

\section{Orden social e identidad de género. México siglos XIX y XX}

Universidad de Guadalajara, Centro de Investigaciones y Estudios

Superiores en Antropología Social, México.

$\mathrm{H}$ ace unos años, varios historiadores mexicanos fueron convocados a responder a la pregunta: "Historia, ¿para qué?" Lo escueto de la interrogante no ocultaba la referencia a dos cuestiones "cuya conexión íntima no autoriza a confundirlas" 1 . Una se refiere a la función o utilidad del sa-

${ }^{1}$ Varios autores, "Historia, ¿para qué?", 2a ed., Siglo XXI, México, 1981, pp. 12-13. ber histórico; la otra, a la legitimidad de ese saber. El discurso histórico posee no sólo un valor cognoscitivo, sino que cumple asimismo una función social cuyas modalidades no son exclusivamente de carácter teórico:

[... el estudio del movimiento de la sociedad, más allá de la validez o legitimidad de los conocimientos que genera, acarrea consecuencias diversas para las confrontaciones y luchas del presente.

\section{Glances into the Past and their Repercussions in the Present}

ALMA DORANTES GONZÁLEZ: Instituto Nacional de Antropología e Historia, México. adorant@cencar.udg.mx

Desacatos, núm. 27, mayo-agosto 2008, pp. 211-213.

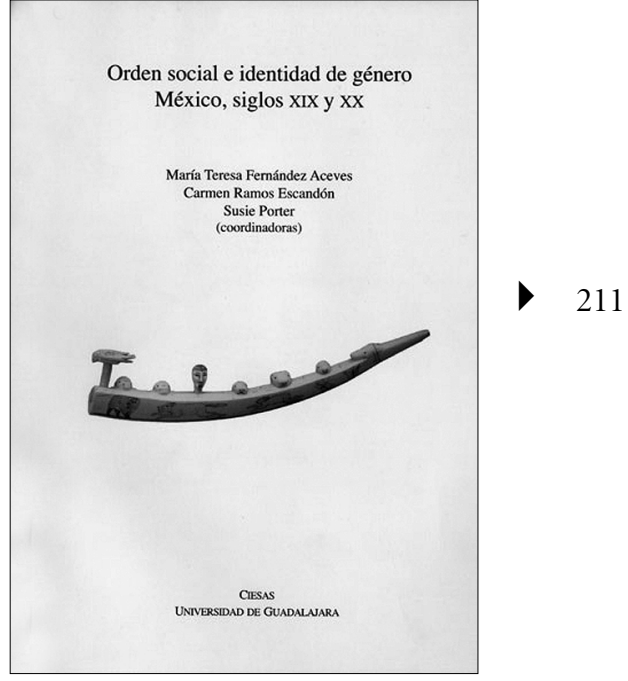

No hay discurso histórico cuya eficacia sea puramente cognoscitiva; todo discurso histórico interviene (se inscribe) en una determinada realidad social donde es más o menos útil para las distintas fuerzas en pugna (ibid.).

Hoy día, la polémica sobre la utilidad y la legitimidad del saber histórico se reaviva a propósito de la historia social y cultural que fundamenta el análisis en conceptos como 'género' y 'poder'. La generación de conocimientos 


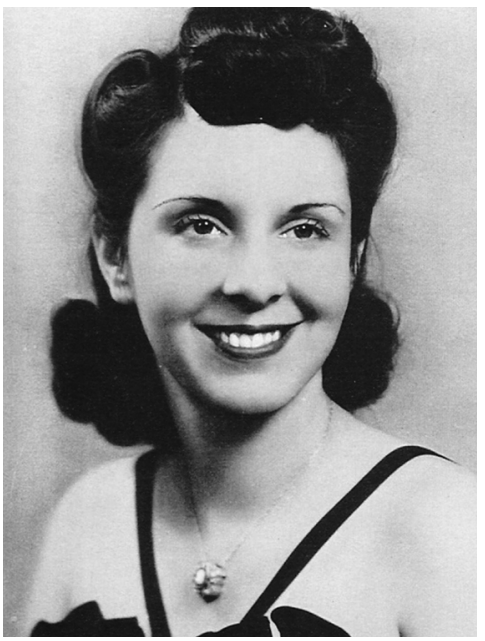

científicos susceptibles de ser utilizados e influir en los campos político y social ha sido el sello distintivo de esa historiografía que, en nuestro medio, todavía suscita actitudes dubitativas, ocasión de la publicación del libro Orden social e identidad de género. México, siglos XIX y XX, podría lanzarse la misma pregunta con una variante: "Historia con perspectiva de género, ¿para qué?”

El potencial innovador $y$ subversivo de la historia de las mujeres y la historia de género no ha sido algo latente, sino una finalidad explícita. Resultó del propósito de interrogar lo histórico-social concediendo prioridad al estudio de las relaciones de poder desigual entre hombres y mujeres y del examen "sobre cómo las instituciones sociales, políticas y educativas reproducen esas relaciones". Como lo explican las coordinadoras de este libro en uno de los ensayos introductorios, esas interrogantes tomaron forma a medida que el "feminismo emer-

gió $[. .$.$] como una metodología que$ corregía las suposiciones aceptadas en la historia y en otras ciencias sociales". Ese cambio de perspectiva suponía, a la vez, transformaciones de mayor envergadura:

La preocupación principal de la historia feminista nunca fue documentar las experiencias de las mujeres en el pasado, aún si ése era el medio más visible con el cual perseguíamos nuestro objetivo. La razón de mirar hacia el pasado era desestabilizar el presente, retar a las instituciones y a las formas de pensar patriarcales que se legitimaban a sí mismas como naturales, hacer que se pensara lo impensable (por ejemplo, separar género de sexo).

Esta "confesión de parte", firmada por Joan Wallach Scott, se encuentra en su trabajo titulado "La historia del feminismo", que aquí se publica. Con gran contundencia, pero también con un tono que conmueve, Wallach Scott hace un exhaustivo recorrido por el camino del movimiento feminista estadounidense, señalando los desafíos y las metas de las historiadoras que estuvieron en la vanguardia en las décadas de 1970 y 1980, las razones por las que se debilitaran los lazos entre el feminismo académico y el político, y la incertidumbre de lo que le depara el futuro a un movimiento social que ha cosechado muchos triunfos $y$, por tanto, ha adquirido compromisos.

En esta publicación del Centro de Investigaciones y Estudios Superiores en Antropología Social (CIESAS) y de la Universidad de Guadalajara participaron catorce investigadores de once instituciones de educación superior e investigación de Alemania, Estados
Unidos y México. A lo largo de sus casi cuatrocientas páginas se comprueba la solidez y la profundidad de las investigaciones, basadas en una gran variedad de fuentes primarias y en la bibliografía más reciente publicada en varios idiomas ${ }^{2}$. Los lectores se percatarán del cuidadoso análisis realizado por los autores que enriquece el campo histórico al incorporar novedosos temas y problemas de estudio, al revelar ángulos de la realidad que quizá sería más cómodo ignorar, y al brindarnos nuevas interpretaciones de asuntos abordados anteriormente bajo otros postulados teóricos y metodológicos.

Cabe destacar el balance que guarda la estructura de la obra dividida en cinco secciones y lo atinado de los títulos de cada una de ellas, que hacen las veces de una brújula que indica con toda claridad el problema de estudio y las principales categorías de análisis que manejan los autores: ciudadanía, nacionalismo, etnicidad, clases sociales y trabajo.

A manera de ejemplo, quiero referirme a los ensayos de Kif AugustineAdams, Susie Porter, Adriana Zavala y Roberto Miranda. Los dos primeros me llamaron la atención por su originalidad; el tercero, por la fehaciente demostración de lo fructífero de una postura revisionista que utiliza la perspectiva de género y arriba a conclusiones novedosas sobre un asunto

\footnotetext{
2 Por ejemplo, deben revisarse con cuidado las quince páginas de notas del trabajo de Fernández, Ramos y Porter, que ofrecen una bibliografía en la que es patente la diversidad de temas tratados en la historia de mujeres y la historia de género.
} 
supuestamente muy bien estudiado. El texto realizado por Roberto Miranda me interesó porque se adentra en una veta que apenas ha comenzado a explorarse - la construcción de la masculinidad - y debido a que utiliza documentos privados, en raros casos accesibles a los historiadores.

Kif Augustine-Adams examinó el problema de la nacionalidad dependiente de la mujer casada a través del caso de las hermanas Tavares, quienes al inicio de la década de 1880 perdieron su nacionalidad mexicana por haber contraído matrimonio civil con extranjeros. Por este hecho, las mujeres se convertían en extranjeras viviendo en su propio país, lo que afectaba sus derechos de propiedad, aunque el autor comprobó que, a este respecto, la aplicación de la ley era selectiva, dependiendo de la clase social y el estatus de las mujeres y sus familias. Con la ley de nacionalidad dependiente se buscaba limitar los derechos de los extranjeros de adquirir bienes raíces, pero a la vez se convirtió en un instrumento para edificar la nación, definir las características que debían poseer sus miembros y asegurar la unidad de la familia y la nacional, que fueron apreciadas como indisolublemente relacionadas.

Bajo el título "Espacios burocráticos, normas de feminidad e identidad de la clase media en México durante la década de 1930", Susie Porter se ocupa de las protestas de grupos de hombres en contra del empleo de mujeres en la administración pública, originadas en la creencia de que los únicos beneficiarios de la expansión de la burocracia estatal, resultado de la Re- volución, debían ser los individuos del sexo masculino. El ingreso de un número elevado de mujeres a los empleos al servicio del Estado, originó un debate público en el que tanto los opositores como los defensores del derecho de las mujeres a ese tipo de trabajo recurrieron, curiosamente, a los mismos argumentos: la necesidad económica, la moralidad sexual de las mujeres y los hábitos de consumo. Porter explica las implicaciones principales de ese debate, que eran, en primera instancia, la definición de la feminidad, en especial de lo que debía ser la mujer de la clase media; en segundo término, la suposición de que los puestos burocráticos debían ser una prerrogativa de esa clase social.

En el artículo "De Santa a india bonita. Género, raza y modernidad en la ciudad de México, 1921", Adriana Zavala coloca bajo su microscopio el concurso de la India Bonita que se organizó en la ciudad de México como parte de los eventos conmemorativos del Centenario de la consumación de la independencia. Zavala está en desacuerdo con los investigadores que han estudiado ese certamen y asegurado "que contribuyó a forjar una esencia nacional auténticamente mexicana y que, junto con otros proyectos indigenistas, sirvió para establecer una ruptura radical con el viejo orden porfirista”. Luego de estudiar de manera extensa el contexto político y cultural, aplicando como categorías analíticas la raza y al género, Zavala afirma que "los discursos paternalistas y racistas, tanto en apoyo como en contra del concurso de la India Bonita, no constituyen una ruptura revolucionaria si- no que, por el contrario, son una reasignación de los modelos ya familiares de la masculinidad competitiva". Concluye, asimismo, que los elementos indígenas apreciados como auténticos por un grupo de destacados revolucionarios "se reducían a una serie de estereotipos parecidos a los de la era porfiriana”.

El trabajo titulado "La vida de un obrero y la construcción de la masculinidad (1890-1940)", de Roberto Miranda, está basado en un archivo personal que contiene las cartas enviadas por el hijo de un sastre del barrio del Santuario en la capital jalisciense a la novia que luego se convirtió en su esposa. Encontrar esta documentación constituye un golpe de suerte de no menor consideración que el reto que plantea: como Miranda señala, analizarlos con un rigor tal que sea posible evitar la descripción anecdótica para elaborar un argumento que resulte de interés tanto para el dueño del archivo como para los historiadores y los científicos sociales. El autor lleva a buen término la tarea que se impuso, aislando los rasgos que en cada etapa de la vida del obrero en cuestión definieron su masculinidad, abriendo así nuestro conocimiento de la familia de la clase trabajadora, la relación entre sus miembros y la naciente industrialización de principios del siglo XX.

Considero indispensable felicitar, para concluir, a los responsables de la recientemente inaugurada Colección de Estudios de Género de la Universidad de Guadalajara, por el profesionalismo de que hicieron gala en la labor editorial. 